\title{
Genetic variation in tree growth, stem form and mortality of Guazuma crinita in slower- and faster-growing plantations in the Peruvian Amazon
}

\author{
By J. C. Weber ${ }^{1), 2), *)}$, C. Sotelo Montes ${ }^{1), 2)}$, J. Cornelius ${ }^{1,3)}$ and J. UGarte ${ }^{1)}$
}

(Received 22 ${ }^{\text {th }}$ March 2010)

\begin{abstract}
Guazuma crinita is an important timber tree with a rotation age of 6-12 years in the Peruvian Amazon. A provenance/progeny test containing 200 families from seven locations (provenances) in the Aguaytía watershed of Peru was established in three zones in the Aguaytía watershed that differ in mean annual rainfall and soil fertility. Farmers managed the replications as plantations. Replications were divided into two groups at 24 months: faster- and slower-growing plantations. The faster-growing plantations were thinned at 32 months. The objectives of this paper are to determine if genetic variation in growth traits (tree height, stem diameter) is relatively greater in the faster-growing plantations, and if there are significant differences in tree mortality and stem bifurcations among provenances and families at 24,36 and 48 months. Variation due to provenances and families and heritability of growth traits were consistently greater in the faster-growing plantations. At 48 months, heritability of growth traits was about twice as large in the faster- than in the slower-growing plantations. There were no significant interactions between zones and either provenances or families. Tree mortality and stem bifurcations in the faster-growing plantations generally did not differ significantly among families, but did differ significantly among provenances. Based on these results and considering its rotation age, we recommend that $G$. crinita families/trees could be selected at 48 months in the faster-growing plantations, the plantations could be transformed into seed orchards and the seed could be used for reforestation throughout the Aguaytía watershed. Results are compared with other tropical hardwoods.
\end{abstract}

Key words: tree improvement, provenance/progeny test, environment, heritability.

\section{Introduction}

Guazuma crinita Mart. (Sterculiaceae family) is a priority timber tree in the Peruvian Amazon (Toledo and RINCóN, 1996). It grows rapidly and can be coppiced for successive harvests. Its moderately dense wood (WEBER and Sotelo Montes, 2008) has useful properties for construction material (VALDIVIA and SotELO MonTES, 1993)

1) World Agroforestry Centre (ICRAF), CIP, Apartado Postal 1558, Lima 12, Peru.

2) World Agroforestry Centre (ICRAF), Sahel Office, B.P. E5118, Bamako, Mali.

3) Agroforestry and Novel Crops Unit, School of Marine and Tropical Biology, James Cook University, PO Box 6811, Cairns, Queensland 4870, Australia.

*) Author for correspondence: John C. WeBer. Telephone: (223) 20235000. Fax: (223) 20228683. E-Mail: johncrweber@aol.com and is used primarily for wall panels and construction poles in Peru. The recommended rotation age is $6-12$ years for these products, but younger trees are often harvested. Natural populations are the principal source of wood, but a rural association is producing seed and seedlings from selected trees for small-scale plantations in the Aguaytía and neighboring watersheds of Peru (Prosema, 2009).

$G$. crinita is a pioneer species that colonizes the floodplain and disturbed secondary forests in the lowland jungle of Peru, Ecuador and Brazil (ENCARNACIón, 1983; FAO, 2007). The breeding system has not been studied, but is assumed to be primarily out-crossing like the majority of tropical trees (BAWA et al., 1990). Trees can begin flowering after 2-3 years in open-grown conditions, and the lightweight, feathered capsules are dispersed by both wind and water (WEBER and SOTELO MONTES, personal observations). These reproductive characteristics probably result in extensive gene flow which, at least for selectively neutral traits, would produce considerable genetic variation within populations but relatively little differentiation among populations (HAMRICK et al., 1992).

As demand for $G$. crinita wood increases in the Peruvian Amazon, genetics research becomes increasingly important to identify superior germplasm for establishing plantations. A key research issue for tree improvement programs is to identify the most appropriate test environments for selecting faster-growing germplasm at an early age. CAMPBELL and SORENSEN (1978) hypothesized that genetic variation in tree growth traits would be relatively greater in test environments where trees grow more rapidly and, therefore, selection would be more effective in such environments.

A provenance/progeny test of $G$. crinita was established on farms in the Aguaytía watershed (Rochon et al., 2007), which is representative in terms of environmental conditions of many other watersheds in the western Peruvian Amazon. Mean annual rainfall and soil fertility increase in general from the lower to the upper part of the watershed. Replications of the provenance/progeny test were established in the lower, middle and upper parts of the watershed, and managed as small-scale plantations. At 24 months, the plantations (i.e., replications) were divided into two groups based on mean growth of the trees: slower-growing and fastergrowing plantations. In this paper, we present results of analyses of tree growth, stem bifurcations and mortality in the provenance/progeny test at 24,36 and 48 months. The major objectives are to determine if genetic varia- 
tion in tree growth is relatively greater in the fastergrowing plantations, and if there are significant differences in tree mortality and stem bifurcations among provenances and families. Results are compared with other tropical hardwood species, and some practical implications for tree improvement programs are discussed.

\section{Materials and Methods}

Sample region, study area, experimental design and management of the provenance / progeny test

Seeds were collected from 200 mother trees in seven natural stands, hereafter referred to as provenances, in the Aguaytía watershed and part of a neighboring watershed in the Peruvian Amazon (Figure 1). Natural stands and scattered individual trees of G. crinita occur throughout the sample region, so it is assumed that the sampled provenances are sub-populations of the same genetic population and are not genetically isolated. In addition, it is assumed that some inbreeding has occurred and continues to occur in these sub-populations. Farmers selected mother trees that had good bole form and no external disease symptoms. The number of selected trees per provenance $(24,63,17,35,23,17$ and 21 , respectively, for provenances 1 to 7 ) was roughly proportional to the total number of trees in each provenance. Selection intensity was only about $20 \%$, so there was probably little difference between the selected trees and the entire population of trees in each provenance (WEBER et al., 2009). To reduce the chance of sampling siblings, at least $100 \mathrm{~m}$ was maintained between any two selected trees. Seedlings of the 200 families were grown in a randomized block experimental design in the nursery for 15 months before being transplanted to the test sites.

The provenance/progeny test was established in the lower, middle and upper parts of the Aguaytía watershed (Figure 1), hereafter called the lower, middle and upper zones. Soil fertility and mean annual rainfall increase in general from the lower to the upper zone, i.e. from Nuevo Requena to San Alejandro. The experimental design was a randomized complete block with 15 replications, hereafter referred to as plantations. The plantations were established on 15 different farms: four in the lower, five in the middle and six in the upper zone. The test was not replicated within farms. In each plantation, the 200 families were randomly assigned to 200 experimental plots, each plot containing two trees, for a total of 400 trees per plantation. Spacing was 2.5 by 2.5 meters within and between rows, and two rows of border trees completely surrounded each plantation. Dead trees were replaced during the first year, but data collected on replants were not included in the analyses.

The plantations were managed by the farmers. Management practices included fertilizer application, cover cropping and manual weeding. Organic compost and rock phosphate were placed in each planting hole, and a nitrogen-fixing cover crop was sown in and around each plantation to improve soil fertility and control soil erosion. Farmers weeded their plantations approximately every 4 weeks during the rainy season, and every 6-8

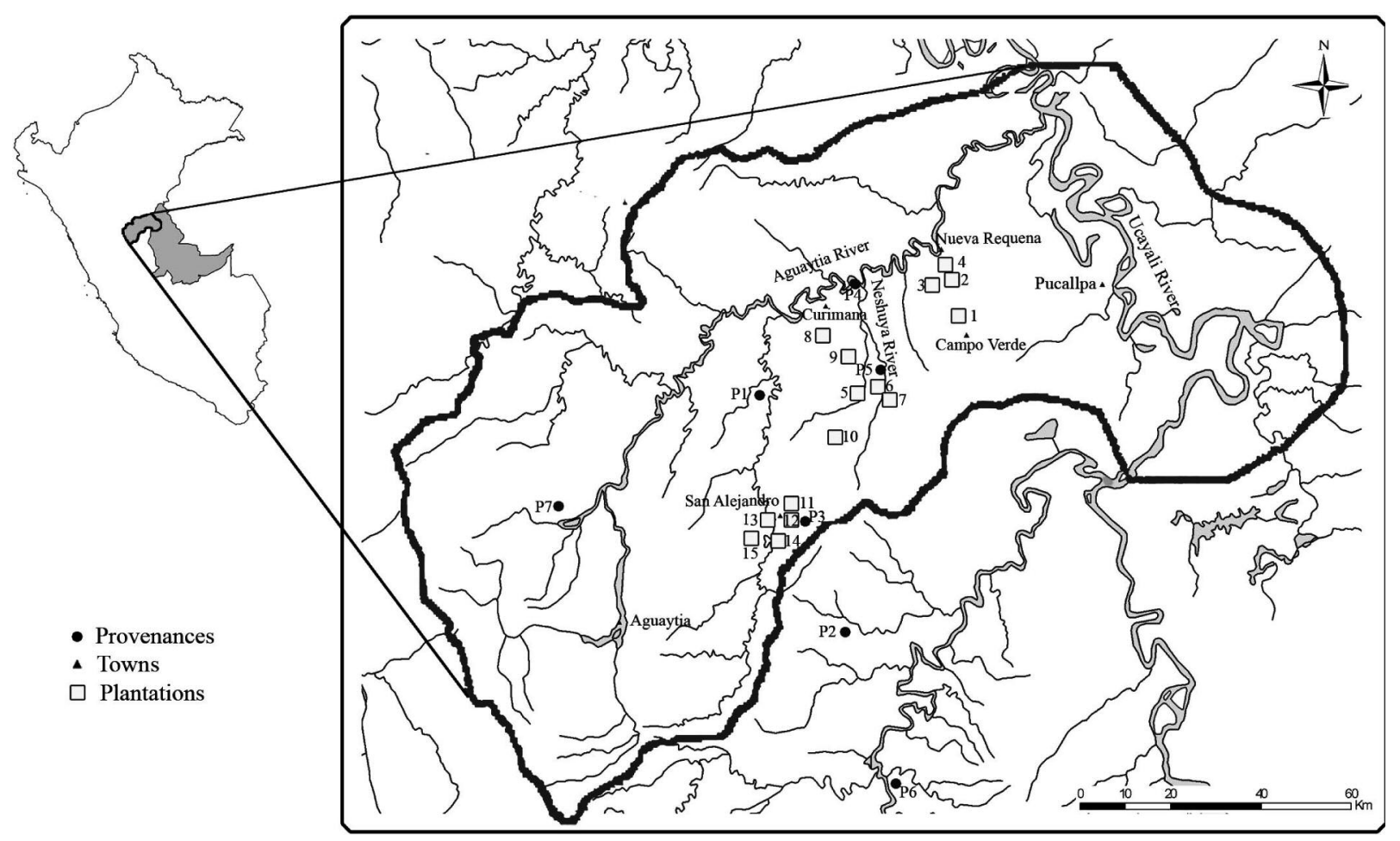

Figure 1. - Map showing the location of the Aguaytía watershed in Peru, the mean location of the mother trees from each provenance (solid circles) and the location of the plantations (open squares). Plantation refers to a replication in the provenance/progeny test. The slower-growing plantations were in the lower and middle zones of the watershed (numbers 1, 2, 3, 4 and 5, 6, 9, respectively), and the faster-growing plantations were in the upper and middle zones of the watershed (numbers $10,11,12,13,14,15$ and 7,8 , respectively). 
weeks during the dry season, but weeding was not systematically done due to time and labor constraints. The relatively large plantation size (about $0.3 \mathrm{ha}$ ) combined with farmers' erratic weeding practices probably affected the differences among plantations and among families within plantations, as well as the stability of provenance and family performance across plantations (RocHON et al., 2007).

Details about the sample region, study area, experimental design and management of the provenance/progeny test are provided elsewhere (Rochon et al., 2007).

\section{Faster-and slower-growing plantations in the provenance/progeny test}

Based on mean tree growth at 24 months, the 15 plantations were divided into a faster-growing and a slowergrowing group. The faster-growing group included all six plantations in the upper zone and two plantations in the middle zone, while the slower-growing group included all four plantations in the lower zone and three plantations in the middle zone (Figure 1). Plantations in the faster- and slower-growing groups are hereafter referred to as the faster- and slower-growing plantations.

The faster-growing plantations were thinned at 32 months. In plots with two living trees, the smaller, less vigorous tree with poorer stem form was cut. In plots with only one living tree, that tree was left even if it was small and had relatively poor stem form. The slowergrowing plantations were not thinned.

\section{Data collection and statistical analyses}

Tree growth, stem bifurcations and mortality were evaluated at 24, 36 and 48 months. Tree height was measured to the nearest $\mathrm{cm}$ using a meter stick or telescopic measuring pole. Stem diameter was measured at $10 \mathrm{~cm}$ above ground (Dia-10) and at breast height (DBH, $1.3 \mathrm{~m}$ above ground, 36 and 48 months only): measurements were recorded to the nearest $\mathrm{mm}$ using callipers or diameter tape. Dia-10 was measured because many trees were too short to measure $\mathrm{DBH}$, especially in the slower growing plantations at 24 months. In addition, G. crinita stems have relatively little taper and are typically coppiced between 10 and $30 \mathrm{~cm}$ above ground. The numbers of dead and living trees and trees with and without stem bifurcations were calculated for each family and provenance.

The SAS $^{\circledR}$ statistical package (SAS InstiTUTE INC., 2004) was used for all analyses. Departure from the normal distribution and homogeneity of variance were tested for the residuals using statistics provided by the UNIVARIATE procedure. Data transformations were not considered necessary to satisfy the assumptions of analysis of variance. The significance level for all tests was $\alpha \leq 0.05$.

Analysis of variance (ANOVA) was used to determine if there were significant differences in tree height and stem diameter due to genetic and environmental factors (GLM procedure, partial sums of squares estimation method). Three sets of ANOVAs were carried out. The first set was based on all plantations at 24 months, and included the following sources of variation: zone (Z), plantation nested within zone $[\operatorname{Plant}(\mathrm{Z})]$, provenance $(\mathrm{P})$, family nested within provenance $[\mathrm{F}(\mathrm{P})]$, interactions $[\mathrm{P} * \mathrm{Z}, \mathrm{P} * \mathrm{Plant}(\mathrm{Z}), \mathrm{F}(\mathrm{P}) * \mathrm{Z}, \mathrm{F}(\mathrm{P}) * \operatorname{Plant}(\mathrm{Z})]$ and residual variation. The second set was based on the slower-growing plantations at 24, 36 and 48 months: sources of variation were the same as above. The third set was based on the faster-growing plantations at 24, 36 and 48 months: sources of variation were the same as above at 24 months, but did not include $\mathrm{F}(\mathrm{P}) * \operatorname{Plant}(\mathrm{Z})$ at 36 and 48 months. In all ANOVAs, zone was fixed and the other factors were random, and F-ratios were used to test all factors. Some F-ratios involved more than one mean square in the denominator ("quasi" F-ratios), and were tested with approximate degrees of freedom (Satterthwaite approximation). Differences in least-squares means of zones were compared using Tukey's "honestly significant difference test".

Variance components were estimated using the restricted maximum likelihood method (VARCOMP procedure). The variance component for each random effect in the ANOVA model was expressed as a percentage of the total variance for the random effects (\%VC).

Individual tree heritability $\left(h_{i}^{2}\right)$ of growth traits was estimated at 24, 36 and/or 48 months only if there was significant variation due to families in the respective ANOVA. We assumed partial inbreeding and estimated additive genetic variance as $3 \sigma_{\mathrm{F}(\mathrm{P})}^{2}$ rather than $4 \sigma_{\mathrm{F}(\mathrm{P})}^{2}$, where $\sigma_{F(P)}^{2}$ is the variance component for families within provenances. We used the multiplier 3 rather than 4 , as others have done (Hodge et al., 2002; HodGe and DvoraK, 2004; Sotelo MonTEs et al., 2006), in order to provide a conservative estimate of $h_{i}^{2}$ under the assumption of partial inbreeding. The denominator of $h^{2}$ included the following variance components: $\sigma_{F(\mathrm{P})}^{2}, \sigma_{\mathrm{F}(\mathrm{P}) * \mathrm{Z}}^{2}$, $\sigma_{F(P) * P l a n t(Z)}^{2}$ and $\sigma^{2}{ }_{\text {Residual }}$ for all analyses at 24 months and for the slower-growing plantations at 36 and 48 months; and $\sigma_{F(P)}^{2}, \sigma_{F(P) * Z}^{2}$ and $\sigma_{\text {Residual }}^{2}$ for analysis of the faster-growing plantations at 36 and 48 months. Standard errors for $h_{i}^{2}$ were calculated using the formula provided by BECKER (1984).

The relationship between growth traits at 24 and 48 months was investigated using simple linear regression and Pearson $r$ correlation coefficients (REG and CORR procedures). Analyses were carried out on family means and individual trees, using all data and separately for the slower- and faster-growing plantations. The independent variables for the regressions were height and Dia-10 at 24 months and the dependent variables were height and Dia-10 at 48 months.

The likelihood ratio chi-square statistic $\left(G^{2}\right.$, FREQ procedure) was used to test whether the frequencies of tree mortality and stem bifurcations were statistically independent of provenances and families. Independence was tested separately for the slower- and faster-growing plantations at 24, 36 and 48 months.

The sample sizes in this test could have reduced the accuracy of some estimates of means and variances. The numbers of progeny per family (maximum 30 if no mortality) and families per provenance $(<20$ in two provenances) were relatively low, reducing the accuracy of estimates of family means and some provenance means. 
In addition, a minimum sample size of 40 is recommended to obtain accurate estimates of variance components (N. MANDEL, personal communication). The number of families (200) was adequate to obtain an accurate estimate of family variance, but the number of provenances (7) was too low to obtain an accurate estimate of provenance variance.

\section{Results}

\section{Genetic and environmental variation in tree height and stem diameter}

Judging from the coefficients of variation (CVs), the slower-growing plantations at 24 months had relatively greater variation in tree height and stem diameter (Dia10) than the faster-growing plantations (Table 1). In the slower-growing plantations, CVs decreased between 24 and 48 months. In the faster-growing plantations, which were thinned at 32 months, CVs decreased between 24 and 36 months but increased slightly between 36 and 48 months.

In the analysis of all plantations at 24 months, there were significant differences in tree height and stem diameter between the three zones (Table 2). Both variables increased from the lower to the upper zone: height $=4.90,8.08$ and $10.58 \mathrm{~m}$, and Dia-10 = 7.9, 10.2 and $12.5 \mathrm{~cm}$, respectively, in the lower, middle and upper zone $(\mathrm{p}<0.001$ for all comparisons between zones).

There was also significant variation in tree height and stem diameter due to provenances and families within provenances in the analysis of all plantations at 24 months (Table 2). The percentage of the phenotypic variation (\%VC) was greater for families than for provenances, but both were small. The majority of the phenotypic variation was due to plantations within zones and the residual. Provenance and family ranks were relatively stable across zones, judging from the non-signifi-

Table 1. - Descriptive statistics of tree height and stem diameter of Guazuma crinita in a provenance/progeny test in the Aguaytía watershed of Peru. Statistics are given for all plantations at 24 months and for the slower- and faster-growing plantations at 24,36 and 48 months.

\begin{tabular}{|c|c|c|c|c|c|c|c|c|c|}
\hline \multirow[b]{2}{*}{ Variables } & \multicolumn{3}{|c|}{ All plantations at 24 months } & \multicolumn{3}{|c|}{ Slower-growing plantations } & \multicolumn{3}{|c|}{ Faster-growing plantations } \\
\hline & Mean & CV $(\%)$ & Range & Mean & $\mathrm{CV}(\%)$ & Range & Mean & $\mathrm{CV}(\%)$ & Range \\
\hline \multicolumn{10}{|l|}{ Height (m) } \\
\hline 24 months & 8.24 & 43.8 & 16.11 & 5.24 & 39.9 & 10.88 & 10.86 & 22.4 & 15.77 \\
\hline 36 months & --- & --- & --- & 6.45 & 36.5 & 12.23 & 13.32 & 18.9 & 18.90 \\
\hline 48 months & --- & --- & -- & 8.13 & 26.9 & 13.25 & 15.20 & 19.7 & 20.10 \\
\hline \multicolumn{10}{|l|}{$\underline{\operatorname{Dia}-10(\mathrm{~cm})}$} \\
\hline 24 months & 10.5 & 33.9 & 19.7 & 8.0 & 33.9 & 15.0 & 12.7 & 21.3 & 19.1 \\
\hline 36 months & --- & --- & --- & 8.7 & 29.4 & 15.4 & 14.3 & 17.7 & 21.7 \\
\hline 48 months & --- & --- & --- & 10.6 & 24.3 & 17.4 & 16.7 & 20.0 & 23.6 \\
\hline$\underline{\mathrm{DBH}}(\mathrm{cm})$ & & & & & & & & & \\
\hline 36 months & --- & --- & --- & 6.3 & 34.5 & 13.8 & 11.7 & 20.6 & 18.2 \\
\hline 48 months & $-\cdots$ & --- & $-\cdots$ & 7.2 & 28.9 & 14.3 & 12.9 & 21.4 & 19.1 \\
\hline
\end{tabular}

Notes: Plantation $=$ a replication in the provenance/progeny test. Height $=$ tree height, Dia-10 $=$ stem diameter at $10 \mathrm{~cm}$ above ground, DBH = stem diameter at breast height $(1.3 \mathrm{~m}) . \mathrm{CV}=$ coefficient of variation. Sample sizes: all plantations at 24 months $=5057$; slower-growing plantations $=2353$ at 24 months, 2195 for height and Dia-10 and 2089 for DBH at 36 months, 1434 at 48 months; faster-growing plantations = 2704 at 24 months (before thinning), 1524 at 36 months, 1478 at 48 months.

Table 2. - Sources of variation of tree height and stem diameter of Guazuma crinita at 24 months in a provenance/progeny test in the Aguaytía watershed of Peru.

\begin{tabular}{|c|c|c|c|c|c|}
\hline \multirow[b]{2}{*}{ Source of variation } & \multirow[b]{2}{*}{ DF } & \multicolumn{2}{|c|}{ Height } & \multicolumn{2}{|c|}{ Dia-10 } \\
\hline & & $p$ & $\% \mathrm{VC}$ & $p$ & $\% \mathrm{VC}$ \\
\hline $\bar{Z}$ & 2 & 0.012 & $\begin{array}{l}-- \\
\end{array}$ & 0.014 & -- \\
\hline $\operatorname{Plant}(Z)$ & 12 & $<0.001$ & 68.6 & $<0.001$ & 42.8 \\
\hline$P$ & 6 & 0.012 & 0.1 & 0.032 & 0.3 \\
\hline $\mathrm{F}(\mathrm{P})$ & 193 & 0.016 & 0.6 & 0.001 & 1.3 \\
\hline$P * Z$ & 12 & 0.977 & 0.0 & 0.783 & 0.0 \\
\hline $\mathrm{P} *$ Plant(Z) & 72 & 0.027 & 0.2 & 0.010 & 0.5 \\
\hline $\mathrm{F}(\mathrm{P}) * \mathrm{Z}$ & 386 & 0.099 & 0.6 & 0.408 & 0.4 \\
\hline $\mathrm{F}(\mathrm{P}) * \operatorname{Plant}(Z)$ & 2201 & $<0.001$ & 17.9 & $<0.001$ & 18.2 \\
\hline Residual & 2172 & -- & 12.0 & -- & 36.5 \\
\hline
\end{tabular}

Notes: Plantation = a replication in the provenance/progeny test. Height $=$ tree height, Dia-10 = stem diameter at $10 \mathrm{~cm}$ above ground. Source of variation: zone $=Z$, plantation nested in zone $=$ Plant $(Z)$, provenance $=P$, family nested in provenance $=\mathrm{F}(\mathrm{P})$, interactions $=\mathrm{P} * \mathrm{Z}, \mathrm{P} * \mathrm{Plant}(\mathrm{Z}), \mathrm{F}(\mathrm{P}) * \mathrm{Z}$ and $\mathrm{F}(\mathrm{P}) * \operatorname{Plant}(\mathrm{Z}) . \mathrm{DF}=\operatorname{degrees}$ of freedom, $\mathrm{p}=$ probability of $\mathrm{F}$ ratio, $\% \mathrm{VC}=$ variance component expressed as percentage of the sum of variance components for random effects (zone $=$ fixed effect, so variance component not calculated). 
Table 3. - Sources of variation of tree height and stem diameter of Guazuma crinita at 24, 36 and 48 months in a provenance/progeny test in the Aguaytía watershed of Peru. Analyses are given for the slower-growing and faster-growing plantations.

\begin{tabular}{|c|c|c|c|c|c|c|c|c|c|c|c|c|c|c|c|c|}
\hline \multirow[b]{3}{*}{ Source } & \multicolumn{4}{|c|}{24 months } & \multicolumn{6}{|c|}{36 months } & \multicolumn{6}{|c|}{48 months } \\
\hline & \multicolumn{2}{|c|}{ Height } & \multicolumn{2}{|c|}{ Dia-10 } & \multicolumn{2}{|c|}{ Height } & \multicolumn{2}{|c|}{ Dia-10 } & \multicolumn{2}{|c|}{ DBH } & \multicolumn{2}{|c|}{ Height } & \multicolumn{2}{|l|}{ Dia-10 } & \multicolumn{2}{|c|}{ DBH } \\
\hline & $\mathrm{p}$ & $\% \mathrm{VC}$ & $\mathrm{p}$ & $\% \mathrm{VC}$ & $\mathrm{p}$ & $\% \mathrm{VC}$ & $\mathrm{p}$ & $\% \mathrm{VC}$ & $\mathrm{p}$ & $\% \mathrm{VC}$ & $p$ & $\% \mathrm{VC}$ & $\mathrm{p}$ & $\% \mathrm{VC}$ & $p$ & $\% \mathrm{VC}$ \\
\hline $\bar{Z}$ & 0.436 & $\cdots$ & 0.731 & $\ldots$ & 0.227 & $\ldots$ & 0.614 & $\ldots$ & 0.327 & $\ldots$ & 0.241 & $\ldots$ & 0.294 & $\ldots$ & 0.737 & -.- \\
\hline Plant(Z) & $<0.001$ & 37.2 & $<0.001$ & 24.5 & $<0.001$ & 36.9 & $<0.001$ & 24.5 & $<0.001$ & 21.1 & $<0.001$ & 17.4 & $<0.001$ & 9.4 & $<0.001$ & 11.5 \\
\hline$P$ & 0.354 & 0.0 & 0.150 & 0.2 & 0.350 & 0.0 & 0.180 & 0.2 & 0.167 & 0.1 & 0.390 & 0.0 & 0.157 & 0.4 & 0.108 & 0.5 \\
\hline $\mathrm{F}(\mathrm{P})$ & 0.362 & 0.2 & 0.235 & 0.4 & 0.201 & 1.0 & 0.234 & 1.1 & 0.402 & 1.1 & 0.028 & 2.8 & 0.025 & 2.8 & 0.024 & 3.2 \\
\hline $\mathrm{P}^{*} \mathrm{Z}$ & 0.931 & 0.0 & 0.840 & 0.0 & 0.939 & 0.0 & 0.807 & 0.0 & 0.865 & 0.0 & 0.721 & 0.0 & 0.858 & 0.0 & 0.876 & 0.0 \\
\hline $\mathrm{P} * \mathrm{P} \operatorname{lant}(\mathrm{Z})$ & 0.002 & 1.2 & $<0.001$ & 1.9 & 0.005 & 0.9 & 0.004 & 1.7 & $<0.001$ & 2.1 & 0.067 & 1.0 & 0.015 & 1.5 & 0.002 & 2.3 \\
\hline$F(P) * Z$ & 0.160 & 1.2 & 0.612 & 0.0 & 0.071 & 1.3 & 0.088 & 1.4 & 0.053 & 1.7 & 0.991 & 0.0 & 0.988 & 0.0 & 0.972 & 0.0 \\
\hline $\mathrm{F}(\mathrm{P})^{*}$ Plant $(\mathrm{Z})$ & $<0.001$ & 34.2 & $<0.001$ & 31.7 & $<0.001$ & 30.5 & $<0.001$ & 19.0 & $<0.001$ & 22.0 & $<0.001$ & 36.1 & $<0.001$ & 18.2 & 0.001 & 21.9 \\
\hline Residual & --- & 26.2 & --- & 41.3 & --- & 29.4 & --- & 52.1 & --- & 51.9 & --- & 42.7 & --- & 67.7 & --- & 60.6 \\
\hline
\end{tabular}

Faster-growing plantations

\begin{tabular}{|c|c|c|c|c|c|c|c|c|c|c|c|c|c|c|c|c|}
\hline \multirow[b]{3}{*}{ Source } & \multicolumn{4}{|c|}{24 months } & \multicolumn{6}{|c|}{36 months } & \multicolumn{6}{|c|}{48 months } \\
\hline & \multicolumn{2}{|c|}{ Height } & \multicolumn{2}{|c|}{ Dia-10 } & \multicolumn{2}{|c|}{ Height } & \multicolumn{2}{|c|}{ Dia-10 } & \multicolumn{2}{|c|}{$\overline{\text { DBH }}$} & \multicolumn{2}{|c|}{ Height } & \multicolumn{2}{|c|}{ Dia-10 } & \multicolumn{2}{|c|}{$\overline{\mathrm{DBH}}$} \\
\hline & $\mathrm{p}$ & $\% \mathrm{VC}$ & p & $\% \mathrm{VC}$ & $p$ & $\% \mathrm{VC}$ & $p$ & $\% \mathrm{VC}$ & p & $\% \mathrm{VC}$ & $\mathrm{p}$ & $\% \mathrm{VC}$ & $p$ & $\% \mathrm{VC}$ & $\mathrm{p}$ & $\% \mathrm{VC}$ \\
\hline $\bar{Z}$ & 0.560 & --- & 0.557 & --- & 0.517 & --- & 0.752 & --- & 0.791 & --- & 0.427 & --- & 0.630 & --- & 0.816 & --- \\
\hline Plant(Z) & $<0.001$ & 59.5 & $<0.00]$ & 27.0 & $<0.001$ & 56.2 & $<0.001$ & 24.7 & $<0.001$ & 29.2 & $<0.001$ & 52.7 & $<0.001$ & 17.4 & $<0.001$ & 23.6 \\
\hline $\mathrm{P}$ & 0.002 & 0.3 & 0.035 & 0.3 & 0.014 & 0.2 & 0.186 & 0.0 & 0.145 & 0.0 & 0.039 & 0.2 & 0.406 & 0.0 & 0.316 & 0.0 \\
\hline $\mathrm{F}(\mathrm{P})$ & $<0.001$ & 1.8 & $<0.001$ & 3.9 & 0.006 & 2.4 & 0.005 & 5.0 & 0.004 & 5.4 & 0.019 & 3.1 & 0.016 & 5.7 & 0.008 & 6.0 \\
\hline$P^{*} \mathrm{Z}$ & 0.958 & 0.0 & 0.838 & 0.0 & 0.910 & 0.0 & 0.852 & 0.0 & 0.853 & 0.0 & 0.903 & 0.0 & 0.870 & 0.0 & 0.892 & 0.0 \\
\hline P*Plant(Z) & 0.534 & 0.0 & 0.551 & 0.0 & 0.485 & 0.0 & 0.123 & 0.2 & 0.112 & 0.2 & 0.326 & 0.1 & 0.081 & 0.5 & 0.219 & 0.0 \\
\hline$F(P)^{*} Z$ & 1.000 & 0.0 & 1.000 & 0.0 & 1.000 & 0.0 & 0.999 & 0.0 & 0.999 & 0.0 & 0.990 & 0.3 & 0.596 & 3.1 & 0.864 & 2.4 \\
\hline Residual & --- & 14.0 & --- & 52.5 & -.- & 41.2 & -.- & 70.1 & -.- & 65.2 & --- & 43.6 & -.- & 73.3 & --- & 68.0 \\
\hline
\end{tabular}

Notes: Plantation $=$ a replication in the provenance/progeny test. Height $=$ tree height, Dia-10 $=$ stem diameter at $10 \mathrm{~cm}$ above ground, $\mathrm{DBH}=$ stem diameter at breast height $(1.3 \mathrm{~m})$. Source $=$ sources of variation: zone $=\mathrm{Z}$, plantation nested in zone $=$ Plant $(Z)$, provenance $=P$, family nested in provenance $=F(P)$, interactions $=P * Z, P * P l a n t(Z), F(P) * Z$ and $F(P) * P l a n t(Z) . p=p r o b a-$ bility of $F$ ratio. Degrees of freedom for slower-growing plantations: $Z=1$; Plant $(Z)=5$ at 24 and 36 months, 4 at 48 months; $P=6$; $\mathrm{F}(\mathrm{P})=193 ; \mathrm{P} * \mathrm{Z}=6 ; \mathrm{P} * \mathrm{Plant}(\mathrm{Z})=30$ at 24 and 36 months, 24 at 48 months; $\mathrm{F}(\mathrm{P}) * \mathrm{Z}=193$ at 24 and 36 months, 185 at 48 months; $\mathrm{F}(\mathrm{P}) *$ Plant $(\mathrm{Z})=912$ at 24 months, 861 for height and Dia-10 and 816 for DBH at 36 months, and 487 at 48 months; Residual = 1006, 899 and 527, respectively, at 24, 36 and 48 months. Degrees of freedom for faster-growing plantations: $\mathrm{Z}=1 ; \mathrm{Plant}(\mathrm{Z})=6$; $\mathrm{P}=6 ; \mathrm{F}(\mathrm{P})=193 ; \mathrm{P} * \mathrm{Z}=6 ; \mathrm{P} * \mathrm{Plant}(\mathrm{Z})=36 ; \mathrm{F}(\mathrm{P}) * \mathrm{Z}=193 ;$ Residual $=1166,1082$ and 1036, respectively, at 24, 36 and 48 months. $\% \mathrm{VC}=$ variance component expressed as percentage of the sum of variance components for random effects (zone $=$ fixed effect, so variance component not calculated).

cant interactions with zones, but they were not stable across plantations within zones.

There was relatively greater genetic variation in the faster- than in the slower-growing plantations (Table 3). At 24 months, there was significant variation in height and Dia-10 due to provenances and families within provenances in the faster- but not in the slower-growing plantations. In all cases, \%VC was greater for families than for provenances. In the faster-growing plantations at 36 and 48 months, variation due to provenances was significant for height, and variation due to families within provenances was significant for height, Dia-10 and DBH. In contrast, in the slower-growing plantations, variation due to provenances was not significant, and variation due to families within provenances was significant for height, Dia-30 and DBH only at 48 months. The \%VC of provenances and families within provenance was generally greater in the faster- than in the slower-growing plantations. The interaction between provenances and plantations within zones was not significant in the faster-growing plantations but was significant in the slower-growing plantations, whereas the interaction between families and plantations within zones was significant in both the slower- and fastergrowing plantations.

Tree height and stem diameter had low $h^{2}$ at 24 months based on the analysis of all plantations (Table 4). It was notably higher in the faster-growing plantations,

Table 4. - Heritability and standard error (in parentheses) of tree height and stem diameter of Guazuma crinita in a provenance/progeny test in the Aguaytía watershed of Peru. Estimates are given only if there was significant variation due to families within provenances (Tables 2 and 3 ).

\begin{tabular}{lrrr}
\hline & Height & Dia-10 & DBH \\
\hline All plantations at 24 months & $0.057(0.025)$ & $0.072(0.027)$ & --- \\
Slower-growing plantations & & & \\
48 months & $0.103(0.079)$ & $0.096(0.079)$ & $0.111(0.080)$ \\
Faster-growing plantations & & & \\
24 months & $0.137(0.054)$ & $0.161(0.057)$ & -- \\
36 months & $0.163(0.092)$ & $0.201(0.095)$ & $0.227(0.097)$ \\
48 months & $0.198(0.096)$ & $0.206(0.097)$ & $0.236(0.099)$ \\
\hline
\end{tabular}

Notes: Plantation $=$ a replication in the provenance/progeny test. Height $=$ tree height $(\mathrm{m})$, Dia-10 $=$ stem diameter at $10 \mathrm{~cm}$ above ground $(\mathrm{cm}), \mathrm{DBH}=$ stem diameter $(\mathrm{cm})$ at breast height $(1.3 \mathrm{~m})$ measured only at 36 and 48 months. 
and was not estimated in the slower-growing plantations because variance due to families was not significant (Table 3). In the faster-growing plantations, $h_{i}^{2}$ of both height and diameter increased between 24 and 48 months (Table 4). At 48 months, $h_{i}^{2}$ was approximately twice as large in the faster- than in the slower-growing plantations: however, considering the large standard errors of $h_{i}^{2}$, the difference cannot be considered statistically significant. Stem diameter, especially DBH, generally had higher $h_{i}^{2}$ than tree height, but neither can this difference be considered statistically significant.

\section{Relationships between growth traits at 24 and 48 months}

Family mean height at 24 months explained about $34 \%$ of the variation in mean height at 48 months in the analysis of all plantations, but the relationship with stem diameter was not significant (Table 5). Family means at 24 months were stronger predictors of means at 48 months in the faster- than in the slower-growing plantations: they explained about $50 \%$ and $30 \%$ of the variation, respectively. To illustrate these relationships, the best 50 families were notionally "selected" based on tree height and stem diameter at 24 and 48 months. The number of families that were among the top 50 at both 24 and 48 months was 25 for height but only 12 for diameter in the analysis of all plantations, 27 for height and 28 for diameter in the slower-growing plantations, 30 for height and 31 for diameter in the faster-growing plantations.
In contrast to family means, individual tree height and stem diameter at 24 months explained about $88 \%$ of the variation in height and diameter at 48 months in the analysis all plantations (Table 5). The relationships were weaker in the separate analyses of the faster- and slower-growing plantations, explaining about $74 \%$ of the variation at 48 months in both cases.

\section{Differences in tree mortality and stem bifurcations among provenances and families}

Tree mortality increased from 16 to $34 \%$ between 24 and 48 months in the test. It was similar in the fasterand slower-growing plantations at 24 and 36 months, but lower in the faster- than in the slower-growing plantations at 48 months (27\% versus $40 \%)$. Tree mortality differed significantly among provenances $\left(G^{2}, \mathrm{p}=0.003\right.$, 0.009 and 0.030 , respectively, at 24,36 and 48 months; $\mathrm{DF}=6$ ) but not among families in the faster-growing plantations. Mortality did not differ significantly among provenances or families in the slower-growing plantations.

Stem bifurcations increased from 4 to $19 \%$ between 24 and 48 months in the test. The frequency of stem bifurcations differed significantly among families in the faster-growing plantations at 36 months and in the slower-growing plantations at 48 months $\left(G^{2}, \mathrm{p}=0.043\right.$ and 0.024 , respectively: $\mathrm{DF}=199$ ). It also differed significantly among provenances in the faster-growing plantations at 48 months $\left(G^{2}, \mathrm{p}=0.043, \mathrm{DF}=6\right)$.

Table 5. - Simple linear regressions predicting tree growth of Guazuma crinita at 48 months from tree growth at 24 months in a provenance/progeny test in the Aguaytía watershed of Peru. Statistically significant regressions are given for family means and trees based on the combined analysis of all plantations, and the separate analyses within the slower- and faster-growing plantations.

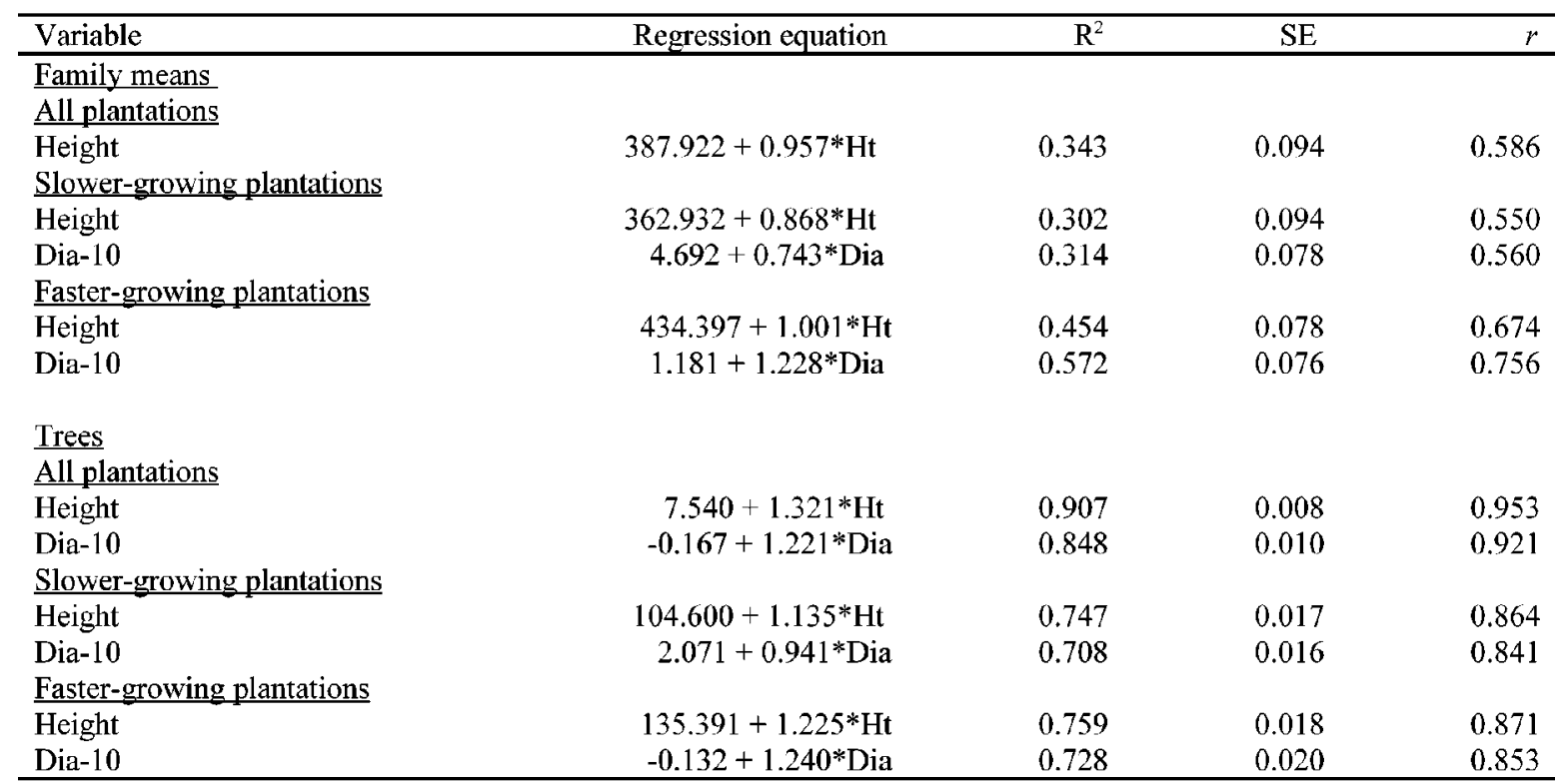

Notes: Plantation = a replication in the provenance/progeny test. Height $=$ tree height $(\mathrm{m})$ and Dia-10 $=$ stem diameter $(\mathrm{cm})$ at $10 \mathrm{~cm}$ above ground. Dependent variables = height and Dia-10 at 48 months. Independent variables $=$ height and Dia-10 at 24 months, abbreviated as Ht and Dia, respectively. $\mathrm{R}^{2}=$ coefficient of determination of regression model; SE = standard error of regression coefficient; $r=$ Pearson correlation coefficient between height and Dia-10 at 24 and 48 months. Probability $<0.001$ for t tests of regression coefficient and Pearson $r$. Sample sizes $=$ 200 for families, 2912 for trees in the analysis of all plantations, 1434 for trees in slower-growing plantations, 1478 for trees in faster-growing plantations. 


\section{Discussion}

Genetic and environmental variation in tree height and stem diameter

The larger coefficients of variation (CV) for tree height and stem diameter in the slower-growing plantations at 24 months were probably related to differences in microenvironmental variation and leaf abscission (ROCHON et al., 2007). The faster-growing plantations were in the upper and middle zones while the slower-growing plantations were in the lower and middle zones of the watershed. Farmers' erratic weeding practices undoubtedly produced considerable spatial and temporal variation in soil moisture, fertility and temperature in the plantations, although these were not monitored. This microenvironmental variation would probably produce the greatest differences in tree growth in zones with the lowest rainfall and least fertile soils, such as the lower zone in this test, and the smallest differences in tree growth in zones with the highest rainfall and most fertile soils, such as the upper zone in this test (BoIvinCHАвот et al., 2004). In addition, if there is phenotypic variation in leaf abscission, one would expect greater variation among trees planted in the drier zones. Partial leaf abscission was rarely observed among trees in plantations in the upper zone, but was common among trees in plantations in the lower zone during the dry season. Since leaf abscission reduces the photosynthetic surface, variation in leaf abscission among neighboring trees could produce substantial variation in growth rates (e.g., DvoraK et al., 1998).

Changes in the CVs of growth traits of $G$. crinita over time were probably related to tree mortality. The slowergrowing, less vigorous trees suffered greater mortality so as they died the standard deviations of height and diameter decreased. In the slower-growing plantations, tree mortality increased by about $24 \%$ between 24 and 48 months and the CVs of height and Dia-10 decreased by about $10 \%$. The decrease in CVs of height and Dia-10 in the faster-growing plantations between 24 and 36 months was of course due primarily to the thinning at 32 months. In the faster-growing plantations, mortality increased by only $2 \%$ between 36 and 48 months and the $\mathrm{CV}$ s of height and Dia-10 increased by $1-2 \%$, reflecting the fact that many of the smaller trees were able to survive in the less densely stocked plantations after thinning.

There were large, significant differences in mean growth of $G$. crinita trees among zones at 24 months, whereas the differences were not significant at 12 months (RocHON et al., 2007). This illustrates the fact that differences in tree growth among planting environments tend to increase over time (e.g., WEBER and SoTElo Montes, 2005; Sotelo Montes et al., 2006; Weber and Sotelo Montes, 2008). Growth traits did not differ significantly among zones in the analyses of the fasterand slower-growing plantations because the slow/fast factors were confounded with zones, i.e. the slowergrowing plantations were in the lower and middle zones and the faster-growing plantations were in the middle and upper zones. Much of the variation in growth was due to plantations and residual variation: this and the significant family by plantation interactions were proba- bly due to the relatively large plantation size and farmers' erratic weeding practices, as reported earlier for this study (ROCHON et al., 2007) and for another provenance/progeny test established on farms in the same watershed (SOTELo MONTES et al., 2006).

Growth of G. crinita trees differed significantly due to provenances and families within provenances at 24 months, but the two genetic components accounted for very little variation, as observed at 12 months (ROCHON et al., 2007). Significant variation in tree growth due to provenances and/or families has also been detected at early ages in other tropical hardwoods in Latin America [e.g., Alnus acuminata Kunth. (CoRNELIUs et al., 1996); Bombacopsis quinata (Jacq.) Dugand (HodGe et al., 2002); Calycophyllum spruceanum (Benth.) Hook. f. ex K. Shum (Sotelo Montes et al., 2003; WeBer and Sotelo Montes, 2005; Sotelo Montes et al., 2006); Prosopis flexuosa D.C. (CoNY, 1996); Sterculia apetala (Jacq.) Karst (DvorAK et al., 1998); Vochysia guatemalensis Sm., J.D. (CoRNELIUS and MESÉN, 1997)].

Families within provenances accounted for more variation in growth than did provenances. This is consistent with our assumption that there is considerable long-distance seed dispersal of $G$. crinita in the watershed, thereby increasing variation within and decreasing variation among provenances (HAMRICK et al., 1992). This suggests that there is more to be gained by selecting the best families within provenances than by selecting the best provenances within the watershed. Similar results were reported for $C$. spruceanum sampled from and tested in the same watershed (Sotelo Montes et al., 2006).

As observed at 12 months (RocHON et al., 2007), provenance and family means for growth traits were relatively stable across zones at 24 months and in the separate analyses of slower- and faster-growing plantations through 48 months. This suggests that the best performing provenances/families of $G$. crinita could be used for reforestation throughout the watershed. Similar results were observed in the provenance/progeny test of C. spruceanum in the same watershed (SotELO MonTES et al., 2006).

Results were consistent with the hypothesis that the expression of genetic variation in growth traits is greater in test environments where trees grow more rapidly (CAMPBELL and SORENSEN, 1978). Variation in growth traits due to families within provenances was consistently greater and variation due to provenances was generally greater in the faster-growing plantations. Similar results were reported for this test at 12 months (Rochon et al., 2007) and for two tests of C. spruceanum in the Peruvian Amazon (Sotelo Montes et al., 2003; Weber and Sotelo Montes, 2005; Sotelo Montes et al., 2006). However, this was not the case in a test of $G$. crinita provenances sampled from several different watersheds in the Peruvian Amazon and established in the Aguaytía watershed (Weber and Sotelo Montes, 2008). In that test, variation due to provenances was relatively greater for growth traits in the zone with the slowest tree growth but for wood density in the zone with the fastest tree growth. In addition, tree growth and wood density were negatively correlated in general, but the magnitude of the correlation differed significant- 
ly among provenances and planting zones. Therefore, we cannot generalize and assume that the expression of genetic variation in growth, or traits correlated with growth, will always be greater in test environments where trees grow more rapidly. The expression of genetic variation in traits and correlations between traits depend on the specific traits, genetic population and test environment (FALCONER and MACKAY, 1996).

Although individual tree heritability $\left(h_{i}^{2}\right)$ of height and stem diameter of $G$. crinita were relatively low in this test, they were within the range of values reported for other tropical hardwoods at an early age (e.g., CoRNELIUS et al., 1996; GREAVEs et al., 1997; SHIMIZU et al., 2002; Sotelo MonTEs et al., 2006). At 24 months, $h_{i}^{2}$ was too low for effective selection of faster-growing families across all plantations. As illustrated with the "selection" example, only $50 \%$ of the 50 families notionally "selected" at 24 months based on mean height across all plantations were among the best 50 families at 48 months.

Heritability of $G$. crinita growth traits was higher in the faster-growing plantations, as observed at 12 months in this test (ROCHON et al., 2007). Similar results were reported for $C$. spruceanum (Sotelo MonTes et al., 2006) and two Eucalyptus species (MACDonALD et al., 1997; GINWALL et al., 2004). Nevertheless, again using the "selection" example, only about $60 \%$ of the 50 G. crinita families notionally "selected" in the fastergrowing plantations at 24 months were among the best 50 families at 48 months.

Estimated $h_{i}^{2}$ of tree height and stem diameter of G. crinita increased between 24 and 48 months in the faster-growing plantations and was $0.20-0.24$ at 48 months. Based on these results and its rotation age (6-12 years), we recommend that selection of fastergrowing $G$. crinita families/trees could be carried out at 48 months in environments where trees grow rapidly. Specifically, the faster-growing plantations could be transformed into seed orchards by roguing the less desirable families/trees. Since there was no significant family by zone interaction in this test, seed from the orchards could be used for reforestation throughout the Aguaytía watershed. Given the strong, positive correlations between growth of individual trees at 24 and 48 months, we assume that the correlations would also be strong between 48 and 72 months (i.e., the onset of the recommended rotation age).

Estimated $h_{i}^{2}$ of $G$. crinita growth traits was very low in the slower-growing plantations so selection would not be very effective in environments where trees grow slowly. Longer-term research is needed to assess whether $h_{i}^{2}$ increases significantly with time in these environments. However, it is unlikely that seed orchards derived from provenance/progeny tests would be economically feasible in these environments due to the slower growth and longer time required for evaluation of genetic variation.

\section{Differences in tree mortality and stem bifurcations among provenances and families}

Tree improvement programs must consider tree mortality and stem form if there is significant genetic varia- tion in these traits. In the faster-growing plantations in the Aguaytía watershed, tree mortality and stem bifurcations were in general randomly distributed among families of $G$. crinita. This suggests that there is little (if any) genetic variation in mortality and stem bifurcations among families established in test sites where trees rapidly, at least up to 48 months. We cannot assume of course that there is little genetic variation in mortality and stem bifurcations among $G$. crinita families after 48 months in this test or in tests in other watersheds. In contrast to this test, there were significant differences in tree mortality and stem bifurcations among families of $C$. spruceanum in the Aguaytía watershed (WEBER et al., 2009), and genetic variation in tree form has been reported in some other tropical hardwoods (e.g., CONY, 1996; CORNELIUs et al., 1996; DVORAK et al., 1998).

There were significant differences in tree mortality and stem bifurcations among provenances of $G$. crinita in the faster-growing plantations. Therefore, if tree improvement programs decide to select the best provenances and families within those provenances, then they should incorporate provenance mortality and stem bifurcations in the selection.

\section{Recommendations for $G$. crinita tree improvement programs}

Based on the results of this study, we recommend that tree improvement programs establish provenance/progeny tests of $G$. crinita in potential planting zones in other watersheds in the Peruvian Amazon and neighboring countries where it has potential for small-scale forestry plantations. The tests should evaluate tree growth, stem form, mortality and commercially important wood properties (such as density) of provenances and families originating from the same watershed in order to assess whether the results of this test can be generalized. The specific research questions of practical interest include the following. Is variation in tree growth and wood properties consistently greater within rather than among provenances in the watershed? Is genetic variation in growth traits consistently greater in planting zones where trees grow more rapidly? Are there significant interactions between provenances/families and planting zones in the watershed? Do genetic and phenotypic correlations between growth traits and wood density differ significantly among provenances and planting zones in the watershed? Do tree mortality and stem bifurcations differ significantly among provenances/families and planting zones in the watershed?

\section{Acknowledgements}

This research was supported by grants to the World Agroforestry Centre (ICRAF) from the Interamerican Development Bank, the Government of Spain, the Governments of Netherlands and Norway as part of the CGIAR Global Initiative for Alternatives to Slash and Burn, the Department for International Development of the United Kingdom, and Winrock International as part of the USAID Alternative Development Program. We wish to thank the participating farmers and technicians 
who worked on this project, NANCY MANDEL (U.S.D.A. Forest Service) for statistical advice, and the anonymous reviewers for their constructive comments on an earlier version of this manuscript.

\section{References}

BAWA, K. S., P. S. Ashton and S. M. NoR (1990): Reproductive ecology of tropical forest plants: management issues, pp 3-13. In: Reproductive Ecology of Tropical Forest Plants, edited by K. S. BAwA and M. HADLEY, UNESCO, Paris.

BECKER, W. A. (1984): Manual of Quantitative Genetics, $4^{\text {th }}$ Edition. Academic Enterprises, Pullman.

Boivin-Chabot, S., H. A. MARgolis and J. C. Weber (2004): Variation in coppice-shoot growth among provenances of Calycophyllum spruceanum Benth. in the Peruvian Amazon Basin. Forest Ecology and Management 198: 249-260.

CAMPBEll, R. K. and F. C. SoREnsen (1978): Effect of test environment on expression of clines and on delimitation of seed zones in Douglas-fir. Theoretical and Applied Genetics 51: 233-46.

Cony, M. A. (1996): Genetic variability in Prosopis flexuosa D.C., a native tree of the Monte phytogeographic province, Argentina. Forest Ecology and Management 87: 41-49.

Cornelius, J., F. Mesén, E. Corea and M. Henson (1996): Variation in growth and form of Alnus acuminata Kunth. grown in Costa Rica. Silvae Genetica 45: 24-30.

CoRnelius, J. and F. Mesén (1997): Provenance and family variation in growth rate, stem straightness, and foliar mineral concentration in Vochysia guatemalensis. Canadian Journal of Forest Research 27: 1103-1109.

Dvorak, W. S., H. Urueña, L. A. Moreno and J. Goforth (1998): Provenance and family variation in Sterculia apetala in Colombia. Forest Ecology and Management 111: 127-135.

ENCARNACIÓN, F. (1983): Nomenclatura de las Especies Forestales Comunes en el Perú. Proyecto PNUD/FAO/ PER/81/002 Fortalecimiento de los Programas de Desarrollo Forestal en la Selva Central, Documento de Trabajo No. 7, Lima.

FALCONNER, D. S. and T. F. C. MACKAY (1996): Introduction to Quantitative Genetics. Addison Wesley Longman Limited, Edinburgh.

FAO (2007): Bolaina blanca. Available from http://www. fao.org/agg/agl/agll/rla128/inia/inia-p4/inia-p4-10.htm.

Ginwal, H. S., P. Kumar, V. K. Sharma, A. K. Mandal and C. E. HARWOOD (2004): Genetic variability and early growth performance of Eucalyptus tereticornis Sm. in provenance cum progeny trials in India. Silvae Genetica 53: $148-153$.

Greaves, B. L., N. M. G. Borralho, C. A. Raymond, R. Evans and P. H. Whiteman (1997): Age-age correlations in, and relationships between basic density and growth in Eucalyptus nitens. Silvae Genetica 46: 264-270.

Hamrick, J. L., M. J. Godt and S. L. Sherman Broyles (1992): Factors influencing levels of genetic diversity in woody plant species. New Forests 6: 95-124.
Hodge, G. R., W. S. Dvorak, H. UrueÑa and L. Rosales (2002): Growth, provenance effects and genetic variation of Bombacopsis quinata in field tests in Venezuela and Colombia. Forest Ecology and Management 158: 273-289.

Hodge, G. R. and W. S. DvoraK (2004): The CAMCORE international provenance/progeny trials of Gmelina arborea: genetic parameters and potential gain. New Forests. 28: 147-166.

MacDonald, A. C., N. M. G. Borralho and B. M. Potts (1997): Genetic variation for growth and wood density in Eucalyptus globulus ssp. globulus in Tasmania (Australia). Silvae Genetica 46: 236-241.

PROSEMA (2009): Asociación de Productores de Semilla Certificada, Plantones y Madera de Alta Calidad de la Cuenca del Aguaytía. Available from http://prosema. wordpress.com

Rochon, C., H. A. Margolis and J. C. Weber (2007): Genetic variation in growth of Guazuma crinita (Mart.) trees at an early age in the Peruvian Amazon. Forest Ecology and Management 243: 291-298.

SAS InstituTe INC. (2004): SAS/STAT Users' Guide, version 9.1. SAS Institute Inc., Cary.

Shimizu, J. Y., L. A. Spence, E. G. Martins and A. J. ARAUJO (2002): Genetic and phenotypic variations in early growth performances of grevillea trees for use in agroforestry systems. International Forestry Review 4: 28-132.

Sotelo Montes, C., H. Vidaurre and J. C. Weber (2003): Variation in stem-growth and branch-wood traits among provenances of Calycophyllum spruceanum Benth. from the Peruvian Amazon. New Forests 26: $1-16$.

Sotelo Montes, C., R. Hernández, J. Beaulieu and J. C. WEBER (2006): Genetic variation and correlations between growth and wood density of Calycophyllum spruceanum Benth. at an early age in the Peruvian Amazon. Silvae Genetica 55: 217-228.

Toledo, E. and C. RINCón (1996): Utilización Industrial de Nuevas Especies Forestales en el Perú. Cámara Nacional Forestal, Instituto Nacional de Recursos Naturales, Organización Internacional de las Maderas Tropicales, Lima.

VAldivia, H. and C. Sotelo Montes (1993): Posibilidad de utilizar la madera rolliza de bolaina blanca (Guazuma crinita Mart.) como material de construcción. Revista Forestal del Perú 20: 87-93.

WeBer, J. C. and C. Sotelo Montes (2005): Variation and correlations among stem growth and wood traits of Calycophyllum spruceanum Benth. from the Peruvian Amazon. Silvae Genetica 54: 31-41.

Weber, J. C. and C. Sotelo Montes (2008): Variation in tree growth and wood density of Guazuma crinita Mart. in the Peruvian Amazon. New Forests 36: 29-52.

Weber, J. C., C. Sotelo Montes, J. Ugarte and A. J. Simons (2009): Phenotypic selection of Calycophyllum spruceanum on farms in the Peruvian Amazon: evaluating a low-intensity selection strategy. Silvae Genetica 58: 172-179. 